\title{
CARACTERIZAÇÃO MORFOLÓGICA DE FRUTOS, SEMENTES, PLÂNTULAS E PLANTAS JOVENS DE MUTAMBA (Guazuma ulmifolia Lam. - STERCULIACEAE) ${ }^{1}$
}

\author{
SEVERINO DE PAIVA SOBRINHO², ALINE GONÇALVES DE SIQUEIRA ${ }^{3}$
}

\begin{abstract}
RESUMO - A Guazuma ulmifolia Lam. é uma espécie arbórea pioneira de ocorrência natural em quase todo o Brasil, desde a Amazônia até o Paraná. Pertence a família Sterculiaceae, sendo recomendada para recuperação de áreas degradadas. O objetivo deste trabalho foi descrever os caracteres morfológicos dos frutos, sementes, plântula e planta jovem. No fruto foram observados: forma, coloração, dimensões, textura, deiscência, e o número de sementes por fruto. Na semente foram observados: coloração, peso de 1000 sementes, forma, tegumento, embrião e endosperma. O estádio de plântula foi considerado até o momento em que tinha apenas os cotilédones e a partir da emissão de folhas passou a ser considerada planta jovem. Os aspectos vegetativos descritos e ilustrados foram: raiz primária, raízes secundárias e terciárias, hipocótilo, epicótilo, cotilédones, caule, folhas e gema apical. Fruto e uma cápsula loculicida globoso, de coloração preta, com faixas estreitas e superfície muricada. Semente de coloração acinzentada e formas variadas, envolta pela testa que quando umedecida torna-se gelatinosa. Embrião axial e contínuo; com cotilédones foliáceos, plicados e que após a emergência são arredondados, verdes e com nervuras. Após a emergência o hipocótilo e a raiz primária são brancos e cilíndricos, mas com passar do tempo se tornam mais escuros. Caule de coloração verde-escura; folhas pecioladas, com nervura principal e secundária; limbo com margem dentada.
\end{abstract}

Termos para indexação: Guazuma ulmifolia, frutos, sementes, plântulas.

\author{
MORPHOLOGICAL CHARACTERIZATION OF FRUITS, SEEDS, SEEDLINGS AND \\ SAPLINGS OF MUTAMBA (Guazuma ulmifolia Lam. - STERCULIACEAE)
}

\begin{abstract}
Guazuma ulmifolia Lam. is pioneer species of natural occurrence in different regions in Brazil. It belongs to the Sterculiaceae family and is indicated for recovery-degraded areas. The objective of this research was to describe and illustrate the morphological aspects of the fruits, seeds, seedlings and juvenile plants. For the study of the fruit, the following aspects were observed: type, color, dimensions, texture, opening and number of seeds per fruit. For the seed the color, weight of 1000 seeds, form, tegument, embryo and endosperm were observed. The seedling stage was considered while it has only cotyledons, the saplings stage was considered after the appearance of the first leaf. The vegetative aspects described and illustrated were: primary, secondary and tertiary roots, hypocotyl, cotyledons, stem, leaf and apical bud. The fruit is a globose loculicidal capsule, with dark coloration, narrow stripes and surface muricate. Graycolored seeds, varied shapes, wrapped by the testa and if humid becomes gelatinous. Axile embryo e and continuous; with foliaceous cotyledons, folded and after emergence they are round, green colored with ribs. After emergence the hypocotyl and primary root are white and cylindrical, but after some time they become darker. Stem is dark-green in color; petiolated leaf, with main and secondary ribs, limb with dentate edge.
\end{abstract}

Index terms: Guazuma ulmifolia, fruit, seeds, seedling.

${ }^{1}$ Submetido em 09/02/2007. Aceito para publicação em 26/11/2007.

${ }^{2} \mathrm{Eng}^{\mathrm{O}} \mathrm{Agr}^{\mathrm{0}} \mathrm{Msc}$. Professor Assistente. Curso de Ciência Biológica, UEG/Unidade de Porangatu, CEP 76.550-000. Porangatu - GO, paivasevero@bol.com.br
${ }^{3}$ Graduanda do Curso de Biologia, UEG/Unidade de Porangatu, alineueg@ hotmail.com, Bolsista PBIC/UEG 


\section{INTRODUÇÃO}

Guazuma ulmifolia Lam. éuma espécie comumnocerrado brasileiro e pertence a família Sterculiaceae, popularmente conhecida como, mutambo, mutamba, fruta-de-macaco, embira, embireira e mutamba verdadeira. Apresenta altura entre $8 \mathrm{~m}$ a $16 \mathrm{~m}$ e tronco entre $30 \mathrm{~cm}$ e $50 \mathrm{~cm}$ de diâmetro (Lorenzi, 2002). Segundo este autor esta espécie tem uma ocorrência em quase todo o país, desde a Amazônia até o Paraná, principalmente nas florestas latifoliada semidecídua. Segundo Barbosa \& Macedo (1993) a ocorrência desta espécie é comum em toda a América Latina.

No Brasil a estação de florescimento se dá no final de setembro até início de novembro, os frutos desta floração amadurecem no próximo ano, nos meses de agosto e setembro (Araújo Neto e Aguiar, 1999).

A morfologia da semente é necessária nas análises de identificação e certificação da qualidade das sementes (Oliveira e Pereira, 1984). Para Kuniyoshi (1983) este conhecimento também pode ser aplicado no manejo, visando à conservação da fauna, mediante estudos da dieta de herbívoros. É importante o conhecimento das estruturas morfológicas para a identificação taxonômica das espécies, principalmente as florestais, onde boa parte é pouco conhecida.

Para os taxonomistas, as diferenças entre plantas, assim como as mudanças que possam ter em comum, são susceptíveis de avaliação em larga escala pelos caracteres morfológicos. Estes caracteres manifestam-se por componentes estruturais das plantas e, o seu valor aprecia-se pela constância. Assim, quanto mais constantes, maior a confiança que neles se pode depositar (Lawrence, 1973).

O estudo morfológico das sementes fornece uma grande quantidade de caracteres taxonômicos e filogenéticos. Apesar dos caracteres externos serem mais utilizados, os caracteres internos são mais confiáveis na classificação. Para Gunn (1972) tanto as características externas como as internas das sementes são pouco modificadas pelo ambiente, constituindose num critério bastante seguro para a identificação.

A identificação das plantas no estádio juvenil conduza três direções principais: contribuir para um melhor entendimento da biologia da espécie, ampliar os estudos taxonômicos e auxiliar em trabalhos de levantamentos ecológicos nos aspectos de regeneração por sementes em condições naturais e na ocupação e no estabelecimento ambiental por qualquer espécie.

O estudo das espécies florestais existentes no cerrado tem sido ao longo do tempo restrito a algumas espécies com elevado interesse econômico. As espécies que não apresentam valor econômico até o momento, muitas vezes são deixadas de lado pela pesquisa. Entretanto, para compreender como ocorre a recuperação florestal natural ou de que forma o homem pode fazer essa recuperação, é necessário o conhecimento destas espécies.

A mutamba é considerada uma espécie importante para a recuperação de áreas degradadas (Barbosa e Macedo, 1993; Lorenzi, 2002) e pertence aos estágios inicias de sucessão secundária, sendo classificada por Ferretti et al. (1995) como sendo secundária inicial. Pode-se dizer que a mutamba é uma espécie pioneira na regeneração de áreas, logo, conhecer o desenvolvimento inicial desta espécie é um passo importante para auxiliar um programa de recuperação de áreas degradas.

É importante conhecer a morfologia de frutos, sementes e plântulas das espécies existentes no cerrado, por que desta forma torna-se mais fácil o estudo e a elaboração de projetos de regeneração e recuperação das áreas degradadas. Estas informações também servem de base para futuros estudos taxonômicos. Portanto, o trabalho teve como objetivo estudar a morfologia externa e interna dos frutos, sementes, plântulas e plantas jovens de Guazuma ulmifolia.

\section{MATERIAL E MÉTODOS}

Os frutos foram colhidos no mês de outubro de 2005 no município de Porangatu - GO, de diferentes matrizes, quando se encontravam no chão e depois foram levados para o Laboratório de Biologia da Unidade Universitária de Porangatu - UEG. No laboratório os frutos foram selecionados, retirando os que apresentavam deformação e sinais de ataque de insetos.

Para a determinar o número de sementes por quilograma e o peso de 1000 sementes foram utilizados 10 subamostras de 100 sementes cada, segundo as Regras para Análise de Sementes (Brasil, 1992). Também foi feita a contagem do número de sementes por fruto, para tanto se utilizou uma amostra de 50 frutos.

Para a descrição da morfologia externa e interna dos frutos e das sementes foram utilizados 100 frutos e 50 sementes, escolhidas aleatoriamente. As observações, quando necessárias, foram feitas com auxílio de lupa. Nos frutos foram observados: tipo, coloração, dimensões, textura, deiscência e número de sementes por fruto. Nas sementes as características morfológicas externas observadas foram: forma, coloração, textura, consistência dos tegumentos e o peso de 1000. As características internas observadas foram: embrião e presença do endosperma. Para facilitar o estudo da morfologia interna as sementes foram hidratadas. $\mathrm{O}$ diâmetro 
e altura dos frutos assim como o tamanho das sementes foram medidos, utilizando-se um paquímetro.

No estudo da fase de plântula 40 sementes foram semeadas sobre papel de filtro umedecido em placa de petri, para realizar as observações, outra parte das sementes foi semeada em areia esterilizada. O estudo foi desenvolvido em ambiente não controlado, com temperatura máxima de $38^{\circ} \mathrm{C}$ e mínima de $26^{\circ} \mathrm{C}$.

Para o acompanhamento do desenvolvimento da plântula e da planta jovem, 20 indivíduos foram obtidos através de semeadura direta em sacos de polietileno preto $(15 \mathrm{~cm} \mathrm{x}$ $25 \mathrm{~cm}$ ), regados diariamente e colocados ao ar livre com temperatura ambiente de no máximo $38^{\circ} \mathrm{C}$ e no mínimo $26^{\circ} \mathrm{C}$. O substrato utilizado foi terra mais esterco bovino curtido, na proporção $3: 1$, adicionando $2,0 \mathrm{~kg}$ de superfosfato simples (por $\mathrm{m}^{3}$ de substrato). Para as descrições morfológicas e ilustrações foram utilizadas plântulas e plantas jovens mais vigorosas. O estádio de plântula foi considerado enquanto havia apenas os cotilédones, já o de planta jovem foi após o surgimento da primeira folha. Os aspectos vegetativos descritos e ilustrados foram: raiz primária, raízes secundárias e terciárias; hipocótilo, epicótilo, cotilédones, caule, folhas e gema apical.

\section{RESULTADOS E DISCUSSÃO}

Os dados morfométricos de frutos e sementes são utilizados em diversos estudos, sendo de grande valor

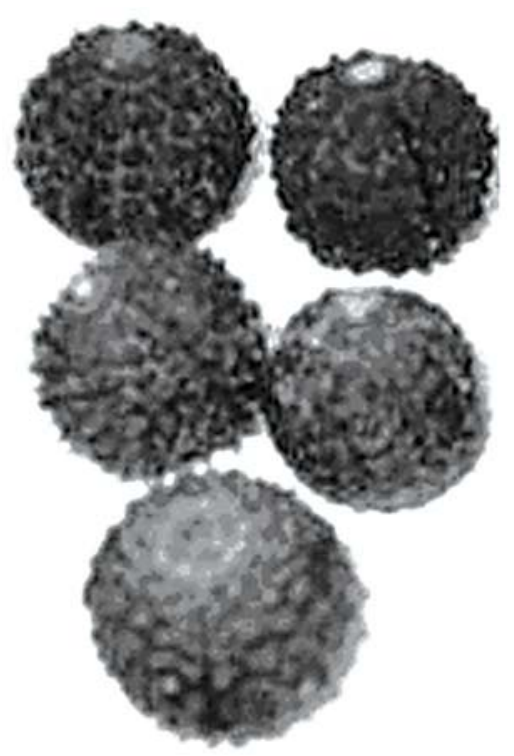

FIGURA 1. Superfície muricada de frutos de mutamba (Guazuma ulmifolia Lam.). ecológico e auxiliam na determinação de espécies, assim como o da disseminação das espécies.

Entre as diversas características de uma semente, as físicas são importantes para a tecnologia de sementes, no planejamento da coleta de sementes e na fase de produção de mudas em viveiro. Pode-se se dizer que um dos grandes problemas na coleta de sementes é a sazonalidade apresentada pelas espécies.

Morfologia do fruto. Cápsula loculicida globosa, de coloração preta, com cinco fendas estreitas, rimosas e com superfície muricada (Figura 1). Estas características também foram descritas por Barroso et al. (1999). Internamente o fruto é duro e seco, com estruturas coriáceas e lenhosas; no centro um eixo longitudinal de consistência duro-lenhosa e com pontas (Figura 2).

Na Tabela 1 observa-se que o diâmetro médio do fruto de mutamba é de $22,04 \mathrm{~mm}$, sendo que este parâmetro variou entre $19 \mathrm{~mm}$ e $27 \mathrm{~mm}$. O menor valor obtido para a altura do fruto foi de $15 \mathrm{~mm}$, o maior de $23 \mathrm{~mm}$ e o valor médio foi de 19,44mm. O número médio de sementes por fruto foi de 87 , mas variou entre frutos de 54 a 107. Estes valores são inferiores aos encontrados por Araújo Neto e Aguiar (1999) que foi de $24,88 \mathrm{~mm}$ para o diâmetro e de $22,61 \mathrm{~mm}$ para a altura.

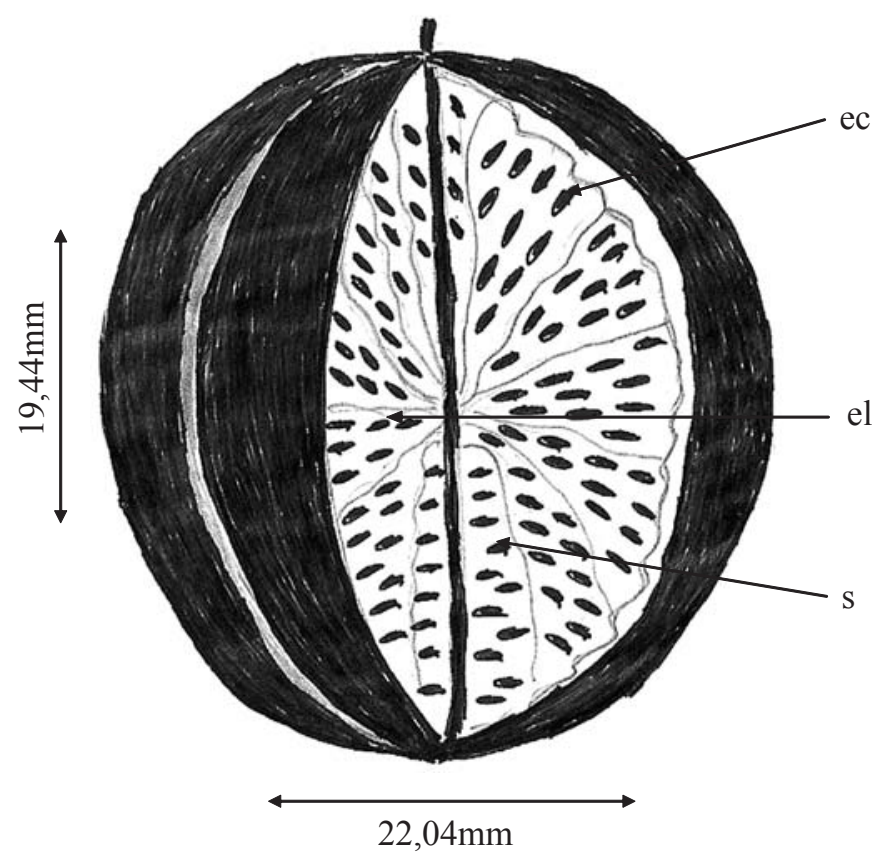

FIGURA 2. Aspectos internos do fruto de mutamba (Guazuma ulmifolia Lam.).

Legenda: ec - estrutura coriácea; el - eixo lenhoso; s - semente. 
TABELA 1. Média dos parâmetros avaliados em frutos e sementes de mutamba (Guazuma ulmifolia Lam.). Porangatu, GO, 2007.

\begin{tabular}{lcccc}
\hline & Média & Desvio padrão & Menor valor & Maior valor \\
\hline Diâmetro $(\mathrm{mm})$ & 22,04 & 1,90 & 19 & 27 \\
Altura $(\mathrm{mm})$ & 19,49 & 1,67 & 15 & 23 \\
$\mathrm{~N}^{\mathrm{o}}$ de sementes/fruto & 87 & 16 & 54 & 107 \\
Peso de 1000 sementes $(\mathrm{g})$ & 7,6 & 0,5 & 7,0 & 8,0 \\
\hline
\end{tabular}

Morfologia da semente. O peso médio de 1000 sementes foi de $7,6 \mathrm{~g}$, com o menor peso de $7,0 \mathrm{~g}$ e o maior de $8,0 \mathrm{~g}$. Em $1,0 \mathrm{~kg}$ de sementes existem em média 130.000 sementes. Semente arredondada, de coloração acinzentada, com 2,0mm de comprimento médio, com destaque para a região da calaza de coloração mais escura; quando umedecidas apresentam tonalidade mais escura. Tegumento duro (dificultando a entrada de água), formado por uma camada membranácea, a testa, e por outra mais dura, o tégmen. Testa quando umedecida torna-se gelatinosa e transparente. Embrião axial e contínuo; com cotilédones foliáceos, plicados (dobrados) e imersos no endosperma gelatinoso e com pontos escuros (Figura 3A), porém não tão branco quanto o embrião (semente não hidratada). Após 24 horas, numa semente seccionada e colocada sobre papel umedecido, observa-se que o embrião ocupa um espaço bem maior em relação ao endosperma (Figura 3B).
Morfologia da plântula. A germinação é do tipo epígea e tem início com a emissão da raiz primária, cerca de quatro dias após a semeadura, que rompe o tegumento na base da semente (Figura 3B). Raiz primária com pêlos de coloração branca; com curvatura acentuada no início (Figura 4) e, em seguida, com crescimento linear. Hipocótilo com cerca de 20,0mm; epicótilo não observado no início, só aparece com a emissão da primeira folha. Epicótilo um pouco menor do que o hipocótilo. Ambos são cilíndricos; hipocótilo inicialmente de coloração branca, mas com o passar do tempo passa para a mesma coloração do epicótilo, verde-escuro. Quando a plântula emerge apresenta cotilédones peciolados, orbiculares, membranáceos, de coloração verde-clara, com bordo inteiro, com nervuras e que se desprendem totalmente do tegumento com cerca de três dias após o início da emergência (Figura $5 \mathrm{~A}$ ), mas permanecem na planta por várias semanas, mesmo quando a planta apresenta dois a três pares de folhas.
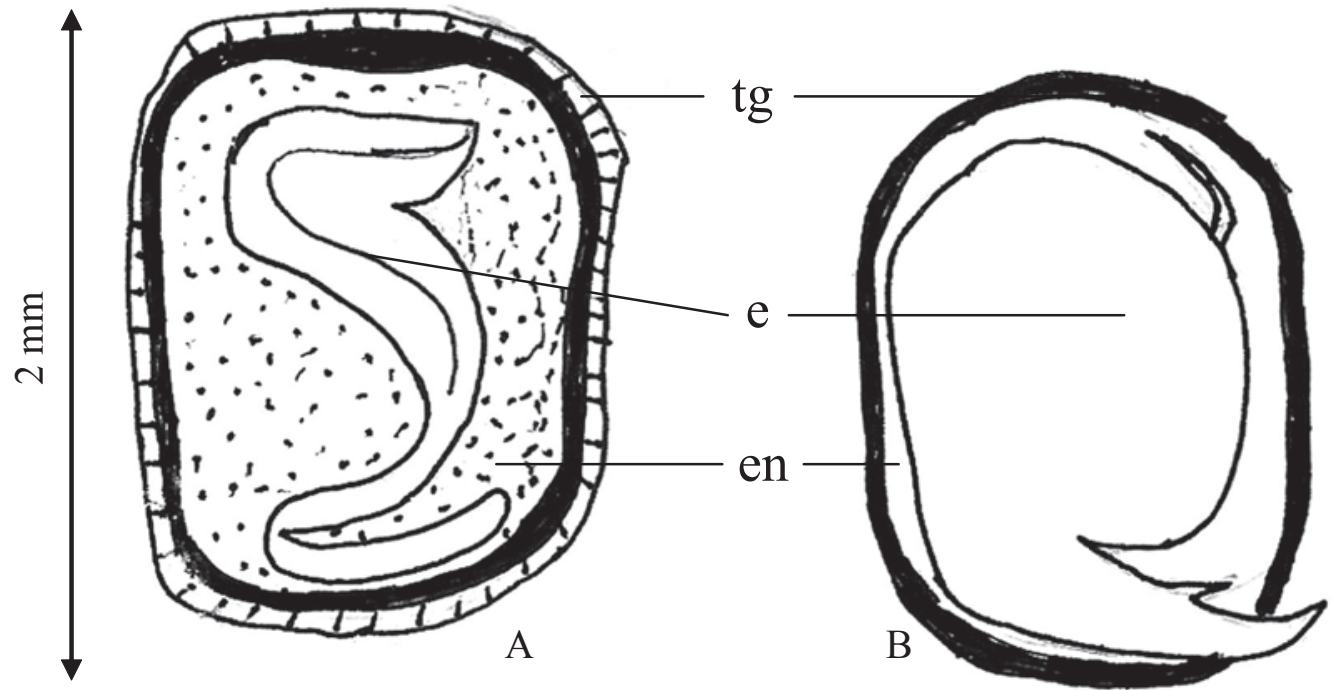

FIGURA 3. Aspectos internos da semente de mutamba (Guazuma ulmifolia Lam.): logo após o corte (A) e após 24 horas sobre papel de filtro umedecido (B).

Legenda: e - embrião; en - endosperma; tg - tegumento. 


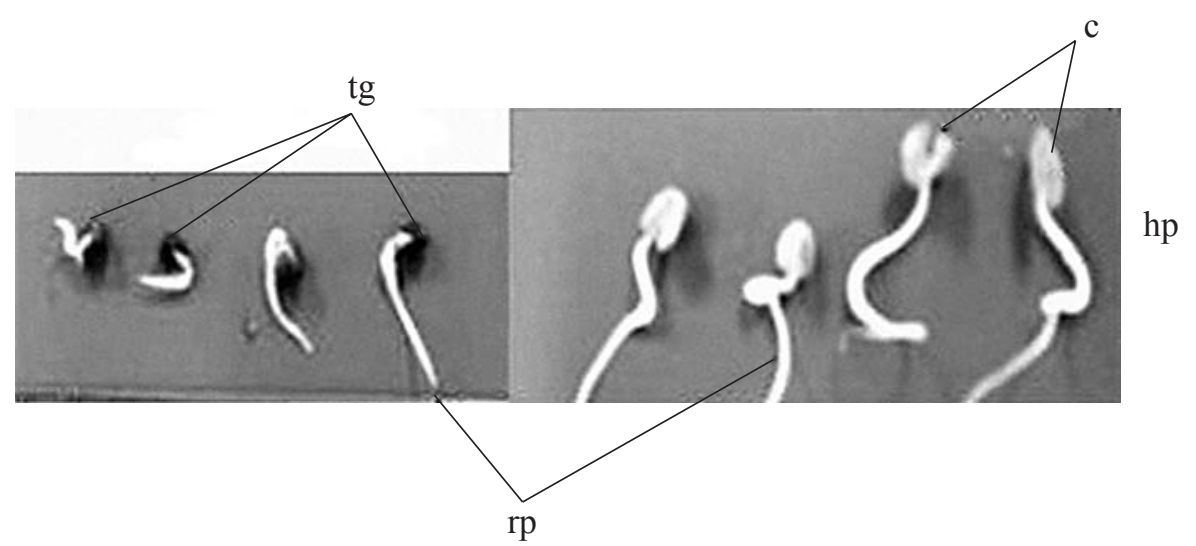

FIGURA 4. Aspectos da germinação de sementes de mutamba (Guazuma ulmifolia Lam.).

Legenda: c - cotilédones; hp - hipocótilo; rp - raiz primária; tg - tegumento.

Morfologia da planta. Aos 30 dias após a emergência a planta apresenta dois pares de folhas e altura média de $5,0 \mathrm{~cm}$ (Figura 5B); aos 60 dias, apresenta três pares de folhas e, em média, $8,0 \mathrm{~cm}$ de altura (Figura 5B). Folhas alternadas, pecioladas, oblongo-lanceoladas, com ápice acuminado, com limbo de margem dentada, com nervura principal e várias secundárias evidentes (Figura 6). O sistema radicular é constituído pela raiz principal e por muitas raízes secundárias
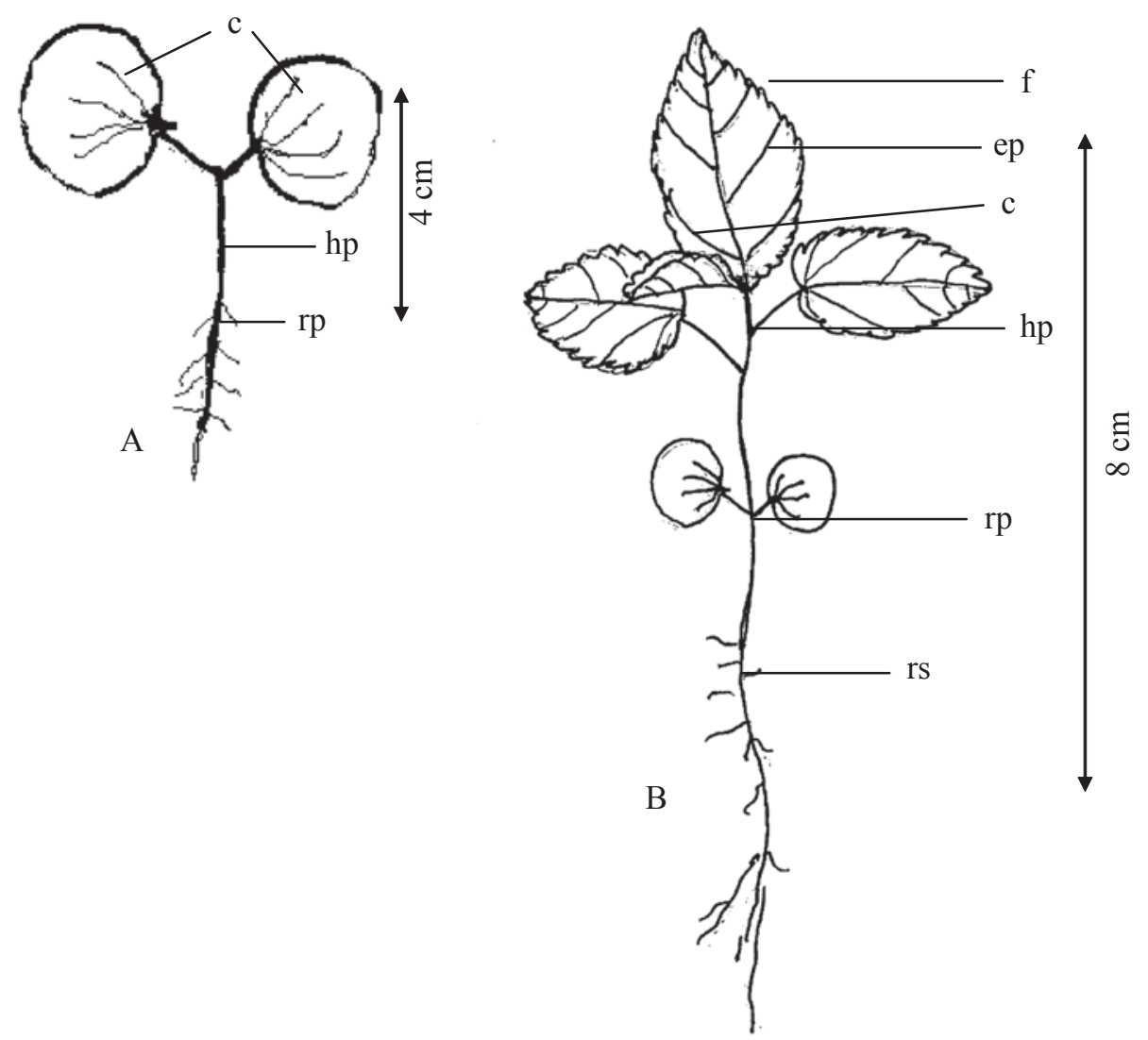

FIGURA 5. Aspecto da plântula (A) e planta jovem (B) de mutamba (Guazuma ulmifolia Lam.).

Legenda: c - cotilédone; ep - epicótilo; $\mathrm{f}$ - folha; $\mathrm{hp}$ - hipocótilo; $\mathrm{rp}$ - raiz primária; rs - raiz secundária. 


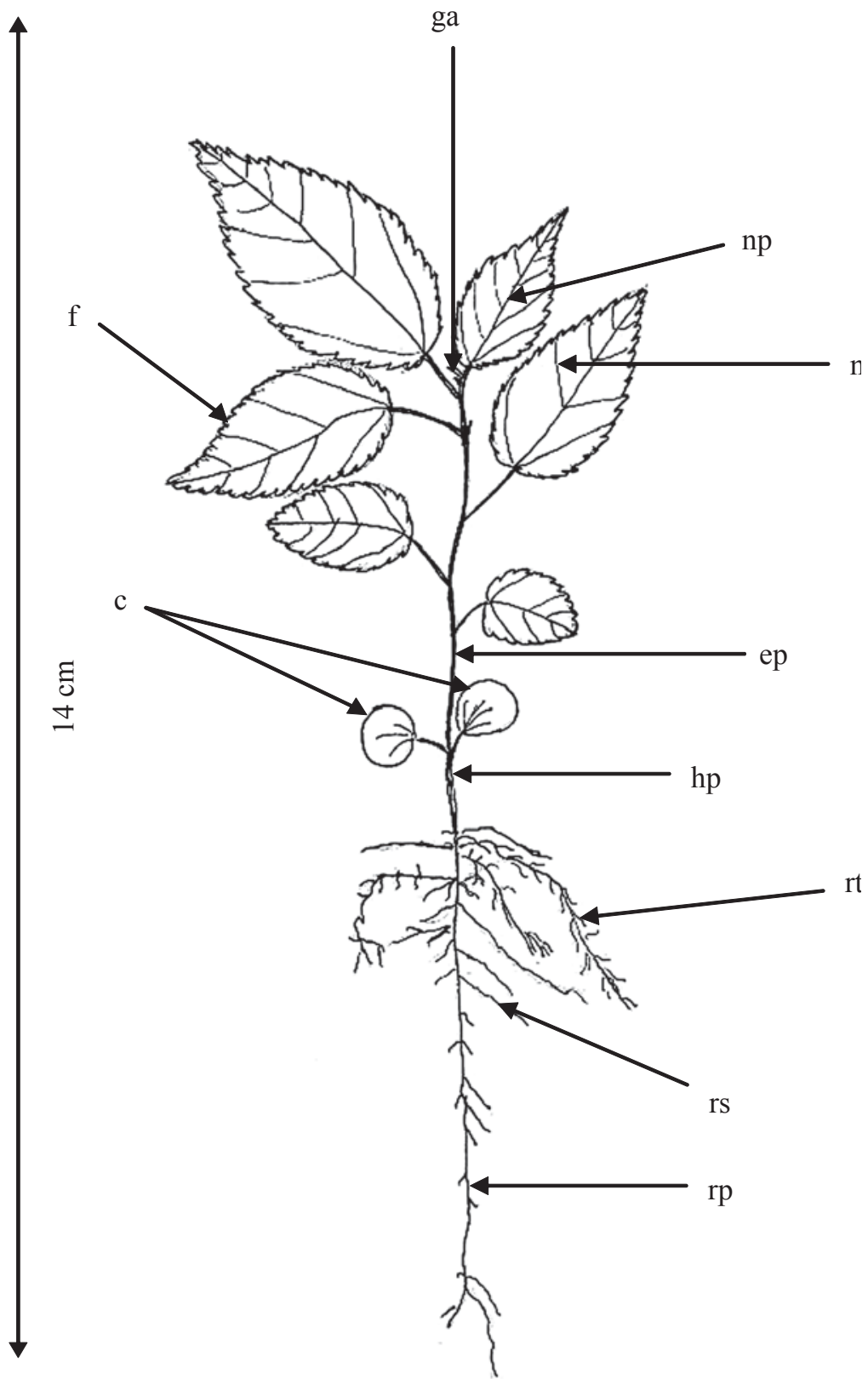

FIGURA 6. Aspectos da planta jovem de mutamba (Guazuma ulmifolia Lam.).

Legenda: c - cotilédones; ep - epicótilo; f - folha; ga - gema apical; hp hipocótilo; np -nervura principal; ns - nervura secundária; rp - raiz primária, rs - raiz secundária; rt - raiz terciária.

e terciárias; o comprimento, em média, é o mesmo da parte aérea da planta, característica esta comum em plantas do cerrado. Gema apical bastante desenvolvida, podendo ser vista facilmente a partir do primeiro par de folhas. Após 30 dias já se observa o surgimento de gemas laterais. Com o aparecimento de cada folha também surge uma gema lateral. Caule reto e de coloração verde-escura.

\section{CONCLUSÕES}

Os aspectos morfológicos do fruto, da semente, da plântula e da planta jovem são homogêneos e constantes. Deste modo, podem ser seguramente empregados em estudos taxonômicos ou ecológicos com a referida espécie. 


\section{REFERÊNCIAS}

ARAÚJO-NETO, J.C.; AGUIAR, I.B. Desarrollo ontogénico de plántulas de Guazuma ulmifolia (Sterculiaceae). Revista de Biologia Tropical, San José, v.47, n.4, p.785-790, 1999.

BARBOSA, J.M.; MACEDO, A.C. Essências florestais nativas de ocorrência no Estado de São Paulo: informações técnicas sobre sementes, grupo ecológico, fenologia e produção de mudas. São Paulo: Instituto de Botânica e Fundação Florestal, 1993. 125p.

BARROSO, M.B; MARIM, M.P.; PEIXOTO, A.L.; ICHASO, C.L.F. Frutos e sementes - morfologia aplicada à sistemática de dicotiledôneas. Viçosa: UFV, 1999. 443p.

BRASIL. Ministério da Agricultura e Reforma Agrária. Regras para análise de sementes. Brasília: SNDA/DNDV/ CLAV, 1992. 365p.

FERRETTI, A.R.; KAGEYAMA, P.Y.; ÁRBOCZ, G.F.; SANTOS, J.D.; BARROS, M.I.A.; LORZA, R.F.; OLIVEIRA, C. Classificação das espécies arbóreas em grupos ecológicos para revegetação com nativas no Estado de São Paulo. Florestal Estatístico, São Paulo, v.3, n.7, p.73-77, 1995.

GUNN, C.R. Seed collecting and identification. In: KOZLOWSKI, T.T. Seed biology. New York: Academic Press, 1972. v.1, p.1-20.

KUNIYOSHI, Y.S. Morfologia da semente e da germinação de 25 espécies arbóreas de uma floresta de araucária. 1983. 233f. Dissertação (Mestrado em Engenharia Florestal) - Universidade Federal do Paraná, Curitiba, 1983.

LAWRENCE, G.H.M. Taxonomia das plantas vasculares. Lisboa: Fundação Caluste Gulbekian, 1973. v.1, 296p.

LORENZI, H. Árvores brasileiras: manual de identificação e cultivo de plantas arbóreas nativas do Brasil. Nova Odessa: Ed Plantarum, 2002. v.1, p.343.

OLIVEIRA, E.C.; PEREIRA, T.S. Morfologia dos frutos alados em Leguminosae - Caesalpinoideae - Martiodendron Gleason, Peltophorum (Vogel) Walpers, Sclerolobium Vogel, Tachigalia Aublet e Schizolobium Vogel. Rodriguesia, Rio de Janeiro, v.36, n.60, p.35-42, 1984. 